\title{
Cannabis Use Is Associated With Patient and Clinical Factors in a Population-Based Sample of Colorectal Cancer Survivors
}

Polly A Newcomb ( $\sim$ pnewcomb@fredhutch.org )

Fred Hutchinson Cancer Research Center https://orcid.org/0000-0001-8786-0043

Mimi Ton

Fred Hutchinson Cancer Research Center

Rachel C Malen

Fred Hutchinson Cancer Research Center

Jamiee L Heffner

Fred Hutchinson Cancer Research Center

Julia D Labadie

Morris Animal Foundation

Amanda I Phipps

Fred Hutchinson Cancer Research Center

Andrea Burnett-Hartman

: Kaiser Permanente Colorado Institute for Health Research

\section{Short Report}

Keywords: marijuana, cannabis, colorectal cancer, survivorship, epidemiology

Posted Date: April 22nd, 2021

DOl: https://doi.org/10.21203/rs.3.rs-431191/v1

License: (c) (i) This work is licensed under a Creative Commons Attribution 4.0 International License. Read Full License

Version of Record: A version of this preprint was published at Cancer Causes \& Control on July 14th, 2021. See the published version at https://doi.org/10.1007/s10552-021-01468-4. 


\section{Abstract}

\section{Purpose}

This study aimed to characterize patient and clinical factors associated with cannabis

(marijuana) use among patients diagnosed with colorectal cancer (CRC).

Methods

We identified CRC patients, diagnosed from 2016-2018, using the Seattle-Puget Sound Surveillance, Epidemiology, and End Results (SEER) cancer registry. CRC patients were recruited via mail and telephone, and participants completed a questionnaire eliciting information on medical history, demographics, and lifestyle factors, including cannabis use. Cancer stage was obtained from SEER registry data.

Results

Of 1,433 survey respondents, 339 (24\%) were current cannabis users. Current cannabis use was associated with younger age at diagnosis, lower $\mathrm{BMI}$, and a higher prevalence of cigarette smoking and alcohol consumption (P-value<0.05). Cannabis use was also associated with lower quality of life scores (FACT-C) and advanced stage cancer (P-value<0.05).

Conclusion

Cannabis use among CRC patients was common. Patients with more advanced disease were more likely to report cannabis use. Use also varied by some personal factors, consistent with patterns in the general population. Given the high prevalence of cannabis use among CRC patients, research is needed to determine the benefits and harms of cannabis use for symptom management in cancer patients.

\section{Introduction}

As of 2020, over two-thirds of US states have legalized medicinal and/or recreational marijuana (cannabis). [1] Changes in laws, policies, and public perception have contributed to a growing prevalence of cannabis use in the US. [2] This increase in use may include cancer patients, where cannabis is purported to have medicinal benefits for symptoms related to cancer or cancer treatment, such as nausea, vomiting, pain, insomnia, and anxiety. [3-5] Our recent work, and the work of others, suggests that approximately $16-24 \%$ of cancer patients are active cannabis users, $[6,7]$ which is approximately twice as high as in the general US population. [2] Furthermore, these prior studies indicate that cannabis use is more common in cancer patients with late stage disease and those who have poor mental or physical quality of life. [6,7] This suggests that cannabis is commonly used by the most vulnerable cancer patients. 
Improvements in the early detection and treatment of cancer has led to a growing population of cancer survivors, in 2020 numbering over 17 million in the US; the number of cancer survivors is expected to increase by 1 million per year, including nearly 150,000 colorectal cancer cases. [8] Given the frequency of cannabis use reported by cancer survivors in prior studies, [6,7] about 2.7 to 4 million cancer survivors in the US may be active cannabis users. Despite this, discussions between cancer survivors and oncology clinicians regarding cannabis use occur only rarely, [6] missing an opportunity to monitor patients for known side-effects of cannabis use, including: cannabis addiction, hypotension, tachycardia, constipation, and a serious fungal infection known as aspergillosis, which can be fatal in immunocompromised patients. $[9,10]$ By characterizing the demographic, behavioral, and clinical factors associated with cannabis use and assessing reasons for use among cancer survivors, physicians can better understand the types of patients who may be using cannabis for symptom management and may benefit from monitoring for potential cannabis side effects.

In this study, we built on our prior work in colorectal cancer (CRC) patients, [7] and evaluated the descriptive epidemiology of cannabis use among a new, population-based sample of recently diagnosed cancer patients from Washington State where medicinal cannabis use was legalized in 1998 and recreational use was legalized in 2012. CRC provides a good model for better understanding cannabis use in men and women diagnosed with cancer due to its high prevalence and use of multimodality treatments with varied side-effects

\section{Methods}

\section{Source Population}

The Puget Sound Surveillance, Epidemiology, and End Results (SEER) registry is a population-based cancer registry which includes data on all cancer cases occurring in the 13-county Puget Sound SEER region. [11,12] SEER employs North American Association of Central Cancer Registries (NAACCR) protocols to identify, confirm, and collect common data elements for each cancer case. [13] Within the Puget Sound SEER registry, we used International Classification of Diseases, Oncology, Version 3 (ICD-03) codes to identify patients with CRC; these included: C180, C182-C189, C199, and C209 (https://seer.cancer.gov/siterecode/icdo3_d01272003/). CRC patients who were diagnosed between April 1, 2016 and December 31, 2018, resided in the Puget Sound SEER region, and were ages 20-74 years at diagnosis were eligible for study recruitment. We excluded patients with a prior CRC diagnosis and those with in situ CRC, and if they could not complete the informed consent and/or questionnaire in English (Supplemental Figure). In a comparison of participants and non-participants based upon SEER reports, we found that the two groups were similar with respect to age, sex, and cancer site and stage.

The cancer registry reporting area for the Puget Sound SEER region is the 13 western Washington counties, with a population size of approximately 5 million. The area includes the major metropolitan areas of the state, as well as substantial rural locales. Washington legalized cannabis for medical indications in 1998 and recreational use in 2012. The wide accessibility of cannabis retail stores has 
made Washington second in the nation in overall sales. Cancer patients eligible for our study therefore have ready access to cannabis through retail outlets throughout the SEER region and state.

\section{Recruitment}

The Puget Sound SEER Program contacted eligible CRC patients via mail about 3-months post-diagnosis to inform them about their potential eligibility for research and to allow them to opt out of research contact. Patients who were alive at the start of recruitment and who did not opt out of research were approached with an introductory study letter and a follow-up telephone call to assess study eligibility and address questions about study participation and consent. All participants provided informed consent, and this study was approved by the Institutional Review Board of the Fred Hutchinson Cancer Research Center.

\section{Questionnaire Data}

Surveys were conducted using the participant preferred methods by telephone interview, online portal, or on paper; the questionnaire was completed an average of 6.9 months after diagnosis (range: 2.9-32.6 months). Participants were initially approached with telephone interview as the primary choice, with online or paper questionnaires offered if they were unable or unwilling to complete via phone. In a structured format, the questionnaire was used to collect detailed data on known and suspected risk factors for colorectal cancer, including smoking history, aspirin and other NSAID use, postmenopausal hormone use by women, family history of colorectal cancer, body size, colorectal cancer screening, other lifestyle and medical factors, and demographics. Information on cannabis use was ascertained through close-ended questions on ever use, use since diagnosis, and frequency of use. The questionnaire also ascertained cannabis use through smoking, vaping, pills, edibles, and other products containing cannabis, and reasons for use, such as recreation, pain management, relaxation/stress relief, sleep aid, nausea/appetite, and other reasons. Patients reported quality of life through measures of physical, functional, social, and emotional well-being, as well as CRC-related concerns through the Functional Assessment of Cancer Therapy-Colon (FACT-C). [14] The study questionnaire was based upon epidemiological data collection instruments used in the NCl-supported multisite Colon Cancer Family Registry with modified questions based on changing behaviors and other exposures over time [15].

\section{SEER Registry Data}

Stage of CRC at diagnosis and tumor location, were obtained for all participants from reports to the SEER registry made by local hospitals.

\section{Statistical Analysis}

We used logistic regression to calculate unadjusted and adjusted odds ratios (aORs) and 95\% confidence intervals (Cls) to compare the odds of "current cannabis use" (use since diagnosis) according to patient demographics, health behaviors, quality of life assessment, and tumor characteristics. We evaluated differences in the odds of current cannabis use by the following demographic factors: age at diagnosis 
(categorically $<45,45-54,55-64, \geq 65$ years), sex (male, female), race (non-Hispanic white, Black, Hispanic, Asian \& Pacific Islander, Other), education (high school or less, some college, college graduate or higher), and annual income (less than $\$ 30,000, \$ 30,000-69,000$, greater than $\$ 70,000$ ). We also compared the odds of current cannabis use according to: $\mathrm{BMI}\left(<25.0,25.0-29.9, \geq 30.0 \mathrm{~kg} / \mathrm{m}^{2}\right)$, tobacco smoking history (never, former, current smoker), alcohol consumption (non-/occasional ( $<1 \mathrm{~g} /$ day), light-to-moderate (1-28 $\mathrm{g} /$ day), heavy (>28 g/day)), ostomy (yes, no), stage at diagnosis (localized, regional, distant), and site (proximal, distal, rectal). In general, variables were collected categorically, with the cut-off points based upon quartiles. BMI was based on categorization of "normal," overweight, and obese according to standard WHO nutritional status. Additionally, we used logistic regression models to measure the association between current cannabis use and quality of life (FACT-C) scores, including FACT-C subcategories (physical, social, emotional, functional well-being and additional concerns related to $\mathrm{CRC}$ ). All estimates of association were mutually adjusted for the potential confounders age, sex, race, BMI, smoking, alcohol consumption, education, and tumor stage, with a term used for missing covariate data (data on covariates were missing in $<5 \%$ of participants). Covariates included in adjusted models were selected a priori based on established or suspected risk factors for CRC.

\section{Results}

A total of 2,345 confirmed eligible CRC patients were identified. Of these, $56(2.4 \%)$ were deceased before enrollment, 294 (12.5\%) were lost to contact, 541 (23.1\%) declined to participate, and 1,454 (62\%) consented to participate. For this analysis, we further excluded those who did not provide information on cannabis use $(n=21)$, resulting in a final study population of 1,433 .

Of the 1,433 respondents, ever use of cannabis was reported by $46 \%(\mathrm{~N}=666)$ of study participants; $24 \%$ $(\mathrm{N}=339)$ of study participants were "current users:" since diagnosis. Among current users, reasons for use included management of stress (54\%), sleep (49\%), and pain (46\%), as well as recreation (41\%); $4 \%$ reported using cannabis for cancer treatment (data not shown). Only $4 \%$ reported cannabis use for recreational purposes only, where symptom use refers to management of stress, sleep, pain, and nausea. Over half of participants reported more than one reason for use. The most common methods of use were smoking (46\%) and vaping ( $41 \%)$; other methods of use included edibles (36\%) and, less frequently, pills (6\%) (data not shown). Patients who used cannabis for only symptomatic purposes were statistically less likely to smoke/inhale than patients who also used it regularly (P-value<0.001). Of those who reported cannabis use for recreational purposes, $88 \%$ reported smoking/inhaling as their method of use; whereas $71 \%$ of those who reported cannabis use for symptom management reported smoking/inhaling cannabis (data not shown).

Compared to participants over age 65 years, the aOR for current use in participants under 45 years was 2.95 (95\% Cl: 1.87-4.65). Compared to Non-Hispanic Whites, Asian \& Pacific Islanders had a lower odds of reporting current cannabis use with an aOR of 0.29 (95\% Cl: $0.14,0.58)$. BMI was inversely associated with cannabis use history. Compared to those with $\mathrm{BMI}<25.0 \mathrm{~kg} / \mathrm{m}^{2}$, the aOR was 0.72 ( $95 \% \mathrm{Cl}$ : 0.53 0.99 ) and 0.55 (95\% Cl: 0.40-0.76) for participants with BMI of $25.0-29.9 \mathrm{~kg} / \mathrm{m}^{2}$ and $30.0+\mathrm{kg} / \mathrm{m}^{2}$, 
respectively. Results also indicated an association with other substance use. The odds of current cannabis use were almost 2-fold greater among current (95\% Cl: 1.21, 2.98) and former smokers (95\% Cl: 1.38-2.45) compared with never smokers. Light-to-moderate and heavy drinkers were 1.41 (95\% Cl: 1.061.88 ) and 2.07 (95\% Cl: 1.39-3.07) times more likely, respectively, to currently use cannabis compared to non-drinkers and occasional drinkers. Lower quality of life scores (lowest quartile) was also associated with current cannabis use with an aOR of 1.52 (95\% Cl: 1.14-2.04). The odds of current cannabis use were about 3-fold greater in participants with distant stage CRC compared with localized CRC $(95 \% \mathrm{Cl}$ : 2.03-4.17). There were no statistically significant associations between current cannabis use and tumor site, ostomy, sex, or education (Table 1).

\section{Discussion}

In this population-based study conducted in a state with legalized recreational and medical cannabis, we found that current cannabis use was reported by approximately one-quarter of CRC cases. Current cannabis use was associated with personal and clinical characteristics such as younger age, race, current smoking and alcohol consumption, lower body mass, lower quality of life, and advanced tumor stage at diagnosis. Participants used cannabis for a range of reasons, often for multiple reasons, as well as through a variety of modalities. Among this group of CRC survivors, the most prevalent modality was smoking; this may have implications for increased risk of negative pulmonary outcomes, including obstructive lung disease and lung cancer. [16,17]

Similar to the results from our prior research in a separate population of CRC survivors, [7] cannabis use was commonly reported in this population-based sample of CRC patients. The frequency of cannabis use in our study population of CRC patients was almost double that reported in the general US population. In the United States, current cannabis use prevalence ranges from 9-13\% according to US National Surveys on Drug and Health and Behavioral Risk Factor Surveillance System (BRFSS) studies. [18,19] Use appears higher in individuals with existing medical conditions, including cancer. [20] In a previous study of cancer patients at a Seattle comprehensive cancer center, $21 \%$ of participants reported being active cannabis users. [6] In our prior study of a cohort of CRC patients with disease diagnosed up to 8 years previously, the prevalence of use in the past month was 16\%. [7] These studies showed, similar to our own findings, that there are individual characteristics that are associated with active cannabis use, specifically younger age, use of tobacco and alcohol, and more advanced disease. Clinicians may find that these, and other characteristics still to be identified, may help inform cannabis discussions with cancer patients, an area identified as an important oncology care gap. [6]

Cancer patients often experience a variety of long- and short-term physical and psychological symptoms as a direct result of cancer and indirectly as a result of its treatment. [21] Physical consequences include nausea, vomiting, pain, and suppressed appetite; psychological sequelae are often reported such as stress, sleep disturbances, depression, and worry. [22,23] Over $40 \%$ of current cannabis users in our study reported that their reasons for use included pain management, relaxation, sleep, appetite, nausea, and vomiting. The efficacy of cannabis in alleviating nausea and vomiting has previously been demonstrated. 
[3] Evidence as to the efficacy of cannabis for control of other symptoms, side effects, and psychological sequelae is anecdotal but widely shared in both cancer patients and the general population. [24] Our study also indicated that cancer patients may be using cannabis for multiple reasons, such as both recreational and symptom management. This may indicate mixing of effects of cannabis use considering many patients site multiple reasons. This speaks to understanding the complexity of reasons for use in cancer patients, only some of which may be secondary to cancer.

Given the significant and often sustained morbidity associated with cancer and cancer treatments, [25,26] identifying effective ways for patients to alleviate symptoms and improve their quality of life is an important priority. $[27,28]$ Current users in this study tended to have later staged cancers and lower quality of life scores (FACT-C) than never/former users. This is also consistent with our prior research in which CRC patients who used cannabis tended to have lower quality of life scores. [7] This likely reflects the scenario that cancer patients with the most severe symptoms are seeking relief through cannabis use. These same patients may also be vulnerable to the potential side-effects of cannabis use, including cannabis addiction and cannabis mediated fungal infections and pneumonia. $[9,10]$ Thus, additional research is needed to determine if cannabis is effective in relieving symptoms associated with cancer and cancer treatment, and to elucidate the risks associated with cannabis use among cancer patients. The absence of evidence-based cannabis use for cancer symptoms limits informed discussions between clinicians and their patients, and may negatively impact decision-making regarding cannabis use during and after cancer treatment. [6]

In depth research is also needed to understand the types of cannabis users among cancer survivors and their different patterns of use and reasons for use. For example, some cancer survivors with advancedstage cancer may use cannabis exclusively for symptom management and not have a history of regular cannabis use prior to their cancer diagnosis. These types of cannabis users may be at low risk for cannabis addiction. Other cancer survivors who use cannabis may have a history of using multiple substances (cannabis, alcohol, tobacco), and these cannabis users may have a higher risk for cannabis addiction. Understanding the types of cannabis users and patterns of use among cancer survivors, particularly if obtained in a longitudinal manner, can help providers recognize patients who may be at higher risk for cannabis use disorders and ensure that these patients receive interventions to prevent or treat cannabis use disorders.

There are some limitations that should be considered in interpreting our results. Our questionnaire elicited details on general cannabis frequency, modes of use, and indication for use in the preceding month. However, more detailed information on cannabis use was lacking, such as potency of products; this is a particular challenge as ingredients in consumer purchases vary widely. Most patients in our study were older adults (>50 years) and the frequency of use declined with age, a relationship that has been previously observed. [29] The lower response proportion in epidemiologic studies may introduce bias if cannabis users are less or more likely to participate than never users or non-current users. However, reassuringly, in our study, those who enrolled were similar in age, sex, race, and cancer characteristics to those who did not enroll (data not shown). The reporting of cannabis may have been constrained by 
disease manifestations, as well as social acceptability. Reassuringly, the prevalence of users was comparable to an anonymous clinic-based survey, also in Washington state. $[6,18,19]$ All patients in our study were diagnosed with a single cancer type and may not be generalizable to cancers with better stage, lower toxicities, and better outcomes. CRC provides a good model for cannabis use after cancer as it provides a snapshot of cannabis use among cancer patients with a variety of symptoms, such as pain, nausea, appetite, sleep disturbances, depression, and anxiety which are also prevalent among other cancer types. However, based upon the results from other studies with broader representation of cancer types, the prevalence of use was similar. [7] Our study may also not be generalizable to other regions of the country, because there are regional differences in the legalization status of cannabis and differences in access to cannabis between medically legalized and fully legalized cannabis environments. Our study was observational which may also limit inferences to causality.

In summary, our results suggest that cannabis use is common among CRC patients and that patients reported cannabis use in order to manage a variety of cancer-related, or cancer treatment-related, symptoms. With changes in the legalization status of cannabis, [30] cannabis accessibility is growing in the cancer patient community. Thus, there is a strong and timely need for additional research to understand the benefits and harms of cancer patients' cannabis use in order for patients and doctors to make informed, evidence-based decisions about the use of cannabis for symptom management.

\section{Declarations}

Acknowledgements: This study was supported by the National Institutes of Health National Cancer Institute under award numbers: R01 CA196337, K05 CA152715, and T32 CA094880. The authors would like to thank the generous study participants and research staff for their contributions.

Funding: PN funded by R01 CA196337, K05 CA152715, and T32 CA094880.

Compliance with ethical standards

Conflicts of interest/Competing interests: The authors declare no potential conflicts of interest

Availability of data and material: Not applicable

Code availability: Not applicable

Ethical approval: This study was conducted in accordance with the ethical standards of the institutional review board at the Fred Hutchinson Cancer Research Center and with the 1964 Helsinki declaration and its later amendments. 


\section{References}

1. Legislatures NCoS (2019) State Medical Marijuana Laws. National Conference of State Legislatures. https://www.ncsl.org/research/health/state-medical-marijuana-laws.aspx.

2. Compton WM, Han B, Hughes A, Jones CM, Blanco C (2017) Use of Marijuana for Medical Purposes Among Adults in the United States. Jama-J Am Med Assoc 317 (2):209-211. doi:10.1001/jama.2016.18900

3. Pergolizzi JV, Jr., Taylor R, LeQuang JA, Zampogna G, Raffa RB (2017) Concise review of the management of iatrogenic emesis using cannabinoids: emphasis on nabilone for chemotherapyinduced nausea and vomiting. Cancer Chemother Pharmacol 79 (3):467-477. doi:10.1007/s00280017-3257-1

4. Rabgay K, Waranuch N, Chaiyakunapruk N, Sawangjit R, Ingkaninan K, Dilokthornsakul P (2019) The effects of cannabis, cannabinoids, and their administration routes on pain control efficacy and safety: A systematic review and network meta-analysis. J Am Pharm Assoc (2003). doi:10.1016/j.japh.2019.07.015

5. Ilgen MA, Bohnert K, Kleinberg F, Jannausch M, Bohnert AS, Walton M, Blow FC (2013) Characteristics of adults seeking medical marijuana certification. Drug Alcohol Depend 132 (3):654659. doi:10.1016/j.drugalcdep.2013.04.019

6. Pergam SA, Woodfield MC, Lee CM, Cheng GS, Baker KK, Marquis SR, Fann JR (2017) Cannabis use among patients at a comprehensive cancer center in a state with legalized medicinal and recreational use. Cancer 123 (22):4488-4497. doi:10.1002/cncr.30879

7. Calcaterra SL, Burnett-Hartman AN, Powers JD, Corley DA, McMullen CM, Pawloski PA, Feigelson HS (2020) A population-based survey to assess the association between cannabis and quality of life among colorectal cancer survivors. BMC cancer 20 (1):373. doi:10.1186/s12885-020-06887-1

8. Siegel RL, Miller KD, Jemal A (2020) Cancer statistics, 2020.70 (1):7-30. doi:10.3322/caac.21590

9. Ecker AH, Lang B, Hogan J, Cucciare MA, Lindsay J (2020) Cannabis use disorder among veterans: Comorbidity and mental health treatment utilization. Journal of substance abuse treatment 109:4649. doi:10.1016/j.jsat.2019.11.003

10. Shen JJ, Shan G, Kim PC, Yoo JW, Dodge-Francis C, Lee YJ (2019) Trends and Related Factors of Cannabis-Associated Emergency Department Visits in the United States: 2006-2014. Journal of addiction medicine 13 (3):193-200. doi:10.1097/adm.0000000000000479

11. Park HS, Lloyd S, Decker RH, Wilson LD, Yu JB (2012) Overview of the Surveillance, Epidemiology, and End Results database: evolution, data variables, and quality assurance. Current problems in cancer 36 (4):183-190. doi:10.1016/j.currproblcancer.2012.03.007

12. Enewold L, Parsons H, Zhao L, Bott D, Rivera DR, Barrett MJ, Virnig BA, Warren JL (2020) Updated Overview of the SEER-Medicare Data: Enhanced Content and Applications. JNCI Monographs 2020 (55):3-13. doi:10.1093/jncimonographs/lgz029 
13. Seiffert JE (1997) Development and use of the North American Association of Central Cancer Registries standards for cancer registries. Topics in health information management 17 (3):35-44

14. Ward WL, Hahn EA, Mo F, Hernandez L, Tulsky DS, Cella D (1999) Reliability and validity of the Functional Assessment of Cancer Therapy-Colorectal (FACT-C) quality of life instrument. Qual Life Res 8 (3):181-195

15. Newcomb PA, Baron J, Cotterchio M, Gallinger S, Grove J, Haile R, Hall D, Hopper JL, Jass J, Le Marchand L, Limburg P, Lindor N, Potter JD, Templeton AS, Thibodeau S, Seminara D (2007) Colon Cancer Family Registry: an international resource for studies of the genetic epidemiology of colon cancer. Cancer Epidemiol Biomarkers Prev 16 (11):2331-2343. doi:10.1158/1055-9965.Epi-07-0648

16. Tetrault JM, Crothers K, Moore BA, Mehra R, Concato J, Fiellin DA (2007) Effects of marijuana smoking on pulmonary function and respiratory complications: a systematic review. Arch Intern Med 167 (3):221-228. doi:10.1001/archinte.167.3.221

17. Aldington S, Harwood M, Cox B, Weatherall M, Beckert L, Hansell A, Pritchard A, Robinson G, Beasley R, Cannabis, Respiratory Disease Research G (2008) Cannabis use and risk of lung cancer: a casecontrol study. The European respiratory journal 31 (2):280-286. doi:10.1183/09031936.00065707

18. Compton WM, Han B, Jones CM, Blanco C, Hughes A (2016) Marijuana use and use disorders in adults in the USA, 2002-14: analysis of annual cross-sectional surveys. Lancet Psychiatry 3 (10):954964. doi:10.1016/S2215-0366(16)30208-5

19. Schauer GL, Njai R, Grant-Lenzy AM (2020) Modes of marijuana use - smoking, vaping, eating, and dabbing: Results from the 2016 BRFSS in 12 States. Drug Alcohol Depen 209:107900. doi:https://doi.org/10.1016/j.drugalcdep.2020.107900

20. Dai H, Richter KP (2019) A National Survey of Marijuana Use Among US Adults With Medical Conditions, 2016-2017. JAMA network open 2 (9)

21. Cleeland CS, Zhao F, Chang VT, Sloan JA, O'Mara AM, Gilman PB, Weiss M, Mendoza TR, Lee JW, Fisch MJ (2013) The symptom burden of cancer: Evidence for a core set of cancer-related and treatment-related symptoms from the Eastern Cooperative Oncology Group Symptom Outcomes and Practice Patterns study. Cancer 119 (24):4333-4340. doi:10.1002/cncr.28376

22. Averyt JC, Nishimoto PW (2014) Psychosocial issues in colorectal cancer survivorship: the top ten questions patients may not be asking. Journal of gastrointestinal oncology 5 (5):395-400. doi:10.3978/j.issn.2078-6891.2014.058

23. Ramsey SD, Berry K, Moinpour C, Giedzinska A, Andersen MR (2002) Quality of life in long term survivors of colorectal cancer. Am J Gastroenterol 97 (5):1228-1234

24. Abrams DI (2016) Integrating cannabis into clinical cancer care. Current oncology (Toronto, Ont) 23 (2):S8-S14. doi:10.3747/co.23.3099

25. Dorn HF, Cutler SJ (1955) Morbidity from cancer in the United States. I. Variation in incidence by age, sex, race, marital status, and geographic region. Public Health Monogr 29:1-121

26. Manton KG, Akushevich I, Kravchenko J (2008) Cancer Mortality and Morbidity Patterns in the U.S. Population. Springer, New York 
27. El-Shami K, Oeffinger KC, Erb NL, Willis A, Bretsch JK, Pratt-Chapman ML, Cannady RS, Wong SL, Rose J, Barbour AL, Stein KD, Sharpe KB, Brooks DD, Cowens-Alvarado RL (2015) American Cancer Society Colorectal Cancer Survivorship Care Guidelines. CA Cancer J Clin 65 (6):427-455. doi:10.3322/caac. 21286

28. Moore AR, Buchanan ND, Fairley TL, Lee Smith J (2015) Public Health Action Model for Cancer Survivorship. Am J Prev Med 49 (6 Suppl 5):S470-476. doi:10.1016/j.amepre.2015.09.001 S07493797(15)00521-8 [pii]

29. Azofeifa A, Mattson ME, Schauer G, McAfee T, Grant A, Lyerla R (2016) National Estimates of Marijuana Use and Related Indicators - National Survey on Drug Use and Health, United States, 20022014. Mmwr Surveill Summ 65 (11):1-Cover3

30. Ishida JH, Zhang AJ, Steigerwald S, Cohen BE, Vali M, Keyhani S (2020) Sources of Information and Beliefs About the Health Effects of Marijuana. J Gen Intern Med 35 (1):153-159. doi:10.1007/s11606-019-05335-6

\section{Tables}

Table 1. Odds ratios comparing current cannabis use among CRC patients in the Puget Sound region of Washington State according to participant characteristics, clinical factors, and quality of life (FACT-C) scores $(\mathrm{N}=1,433)$. 


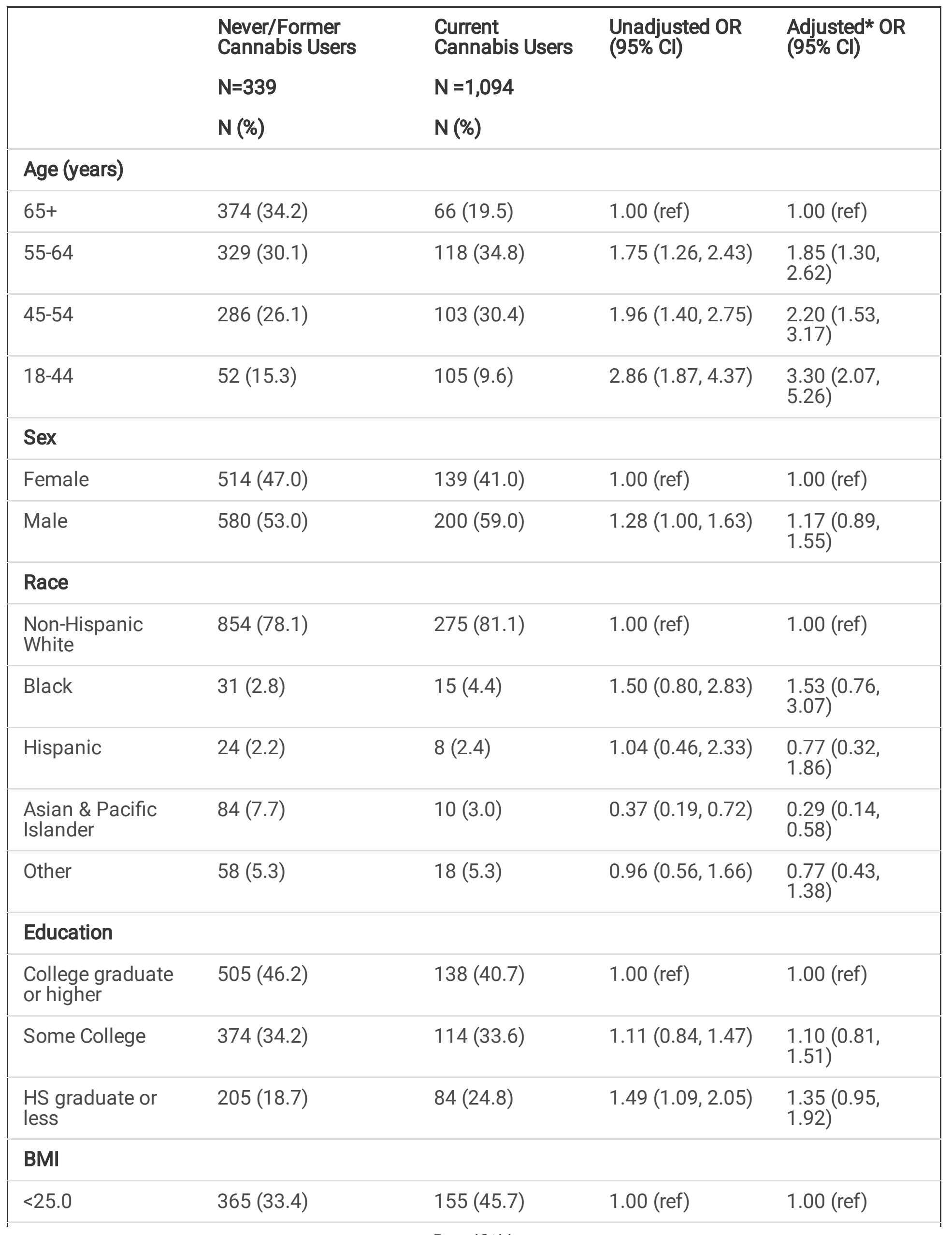




\begin{tabular}{|c|c|c|c|c|}
\hline 25.0-29.9 & $340(31.1)$ & $97(28.6)$ & $0.70(0.52,0.94)$ & $\begin{array}{l}0.65(0.48, \\
0.90)\end{array}$ \\
\hline $30.0+$ & 359 (32.8) & $81(23.9)$ & $0.55(0.41,0.75)$ & $\begin{array}{l}0.49(0.35, \\
0.68)\end{array}$ \\
\hline \multicolumn{5}{|l|}{ Smoking } \\
\hline Never & 647 (59.1) & 151 (44.5) & 1.00 (ref) & 1.00 (ref) \\
\hline Former & 359 (32.8) & 145 (42.8) & $1.72(1.33,2.24)$ & $\begin{array}{l}1.90(1.42, \\
2.54)\end{array}$ \\
\hline Current & $83(7.6)$ & $41(12.1)$ & $2.11(1.39,3.18)$ & $\begin{array}{l}1.82(1.15, \\
2.88)\end{array}$ \\
\hline \multicolumn{5}{|l|}{ Alcohol } \\
\hline $\begin{array}{l}\text { Non-/Occasional } \\
\text { Drinkers } \\
(<1 \mathrm{~g} / \text { day })\end{array}$ & $576(52.7)$ & 132 (38.9) & 1.00 (ref) & 1.00 (ref) \\
\hline $\begin{array}{l}\text { Light-to-Moderate } \\
\text { Drinkers } \\
\text { (1-28 g/day) }\end{array}$ & $394(36.0)$ & 138 (40.7) & $1.50(1.15,1.96)$ & $\begin{array}{l}1.36(1.01, \\
1.83)\end{array}$ \\
\hline $\begin{array}{l}\text { Heavy Drinkers } \\
\text { (>28 g/day) }\end{array}$ & $109(10.0)$ & $63(18.6)$ & $2.48(1.73,3.55)$ & $\begin{array}{l}1.97(1.32, \\
2.96)\end{array}$ \\
\hline \multicolumn{5}{|l|}{ FACT-C } \\
\hline Lowest quartile & $230(21.0)$ & $114(33.6)$ & $1.91(1.46,2.51)$ & $\begin{array}{l}1.51(1.12, \\
2.02)\end{array}$ \\
\hline \multicolumn{5}{|l|}{ Stage } \\
\hline Localized & 447 (40.9) & 75 (22.1) & 1.00 (ref) & 1.00 (ref) \\
\hline Regional & 455 (41.6) & $162(47.8)$ & $2.08(1.54,2.79)$ & $\begin{array}{l}2.11(1.54, \\
2.90)\end{array}$ \\
\hline Distant & $167(15.3)$ & $96(28.3)$ & $3.35(2.37,4.73)$ & $\begin{array}{l}3.12(2.15, \\
4.52)\end{array}$ \\
\hline \multicolumn{5}{|l|}{ Site } \\
\hline Proximal & 359 (32.8) & $101(29.8)$ & 1.00 (ref) & 1.00 (ref) \\
\hline Distal & $309(28.2)$ & $107(31.6)$ & $1.26(0.92,1.71)$ & $\begin{array}{l}1.11(0.79, \\
1.56)\end{array}$ \\
\hline Rectal & 408 (37.3) & 128 (37.8) & $1.14(0.85,1.53)$ & $\begin{array}{l}0.84(0.60, \\
1.16)\end{array}$ \\
\hline Ostomy & & & & \\
\hline
\end{tabular}




\begin{tabular}{|lllll|} 
No Ostomy & $887(81.1)$ & $252(74.3)$ & $1.00($ ref $)$ & 1.00 (ref) \\
\hline Ostomy & $203(18.6)$ & $86(25.4)$ & $1.49(1.12,1.99)$ & $1.09(0.80$, \\
& & & & $1.49)$ \\
\hline
\end{tabular}

*Adjusted for age, sex, race, BMI, smoking status, alcohol, education, and tumor stage 